\title{
Endoscopic ultrasound-guided pancreatic pseudocyst drainage with lumen-apposing metal stents or plastic double-pigtail stents: A multifactorial analysis
}

\author{
Nan Ge${ }^{1}$, Jinlong Hu${ }^{1}$, Siyu Sun ${ }^{1}$, Enqiang Linghu ${ }^{2}$, Zhendong Jin ${ }^{3}$, Zhaoshen $\mathrm{Li}^{3}$ \\ ${ }^{1}$ Endoscopy center, Shengjing Hospital of China Medical University, \\ Shenyang 110004, Liaoning Province, China; \\ 2Department of Gastroenterology and Hepatology, Chinese PLA General Hospital, Beijing, China; \\ ${ }^{3}$ Department of Gastroenterology, Changhai Hospital, the Second Military Medical University, Shanghai, China
}

\section{ABSTRACT}

Objective: To compare the efficiency of plastic and metal stents for symptomatic pancreatic pseudocyst (PP) drainage and analyze other main associated factors that affect the outcome of drainage therapy. Method: Rates of technical and clinical success, procedure-related side effects (hemorrhage, stent migration, and cyst rupture), reinterventions, and duration of hospital stay. Results: There were 52 patients, 40 patients underwent plastic stent placement and 12 patients underwent lumen-apposing metal stent (LAMS) placement. The total rate of technical success was $100 \%$. The total rate of clinical success was $100 \%$. The total rate of adverse events was $7.7 \%(4 / 52)$. On multiple logistic regression analysis, the use of plastic stents $(P<0.05$, Exp $B=12.168)$ and the presence of a large cyst $(P<0.05$, Exp $B=1.036)$ were shown to significantly increase the risk of reintervention. On multivariate linear regression analysis, etiology of pseudocyst $(P<0.05, \mathrm{~B}=-8.427,-9.785,-5.514)$ was associated with prolonged hospital stent, while stent type was not shown be a factor $(P>0.05)$. Conclusion: Both plastic and LAMSs are proven to be highly efficient in PP drainage. The LAMS is superior in preventing complications such as migration and cyst leakage and reducing the rate of reintervention.

Key words: pancreatic pseudocyst, lumen-apposing metal stents, endoscopic ultrasound, plastic double pigtail stents

Address for Correspondence: Prof. Siyu Sun, Endoscopy Center Shengjing Hospital of China Medical University, No. 36, Sanhao Street, Shenyang 110004, Liaoning Province, China.Email: sunsy@sj-hospital.org

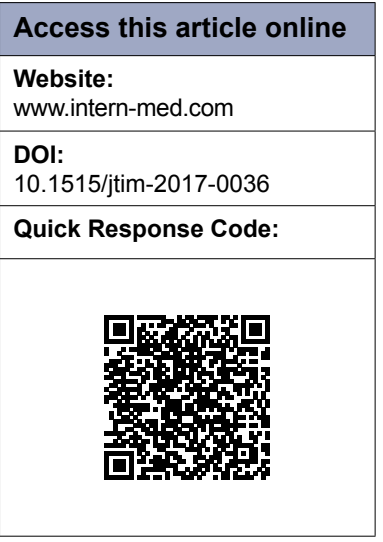

\section{INTRODUCTION}

Endoscopic ultrasound (EUS)-guided puncture and drainage is a widely accepted nonsurgical intervention for pancreatic pseudocysts (PPs). ${ }^{[1-3]}$ Endoscopic interventions include endoscopic cystogastrostomy, balloon dilation of the fistula, endoscopic necrosectomy, and placement of double-pigtail stents for drainage. Recently, covered self-expandable metal stents (CSEMS), which have a lumenapposing design and are used to drain fluid collections, have been studied. ${ }^{[4-7]}$ However, the efficiency of plastic stents and lumen-apposing metal stents (LAMSs) is inconsistent between studies. ${ }^{[8]}$ The aim of this study is to identify whether stent type can affect the clinical outcome and study other risk factors that may also affect the outcome.

\section{PATIENTS AND METHODS}

Inclusion criteria for this study are as follows: (1) PP confirmed by CT and EUS; (2) PP presenting with severe symptoms such as abdominal pain, abdominal distension, duodenal obstruction, or biliary obstruction; or (3) asymptomatic patient with PP larger than $5 \mathrm{~cm}$ (considered a relative indication for drainage therapy in order to avoid future serious complications, such as disruption or infection). Exclusion criteria were (1) walled-off pancreatic necrosis; (2) thin, irregular pseudocyst wall; (3) coagulopathy; or (4) unconfirmed diagnosis. All patients provided informed consent for the procedure. Complete blood counts, prothrombin time, and partial thromboplastin time were normal for all patients. 


\section{Main outcome measurement}

Technical success is defined as accomplishment of stent placement. Clinical success is the resolution of clinical symptoms in combination with a decrease in the size of the PPs to $3 \mathrm{~cm}$ on imaging (mainly EUS or CT) within 3 months. Procedure-related side effects included hemorrhage, stent migration into the cyst, cyst rupture with the use of cystotome, and severe infection. Reinterventions are endoscopic treatments performed after the initial EUSguided stent placement. Failures include residual clinical symptoms, cyst reduction less than $50 \%$ in 3 months, or altered to open surgery. Hospital stay is calculated from the day of the initial EUS-guided drainage in hospital to the day of discharge.

\section{Devices}

Longitudinal echoendoscope (PENTAXEG3830UT, Pentax Corporation, Japan) with a working channel of $3.8 \mathrm{~mm}$ accessible to a $10 \mathrm{Fr}$ stent was used. Echo-Tip Ultra needle (19-G, Wilson-Cook Medic, USA) with a lumen of $0.8 \mathrm{~mm}$ in diameter was fitted to a 0.035 -inch guidewire (Tracer metro direct wire guide, $0.035 \mathrm{inch} / 480$ $\mathrm{mm}$, Wilson Cook Medical Inc, USA). Cystotome (10-Fr, Wilson-Cook Medic) was used to dilate the tract and create a large fistula. A nasobiliary drainage catheter (7-Fr, WilsonCook Medic) was used for drainage of the peritoneum or infected cyst. A double-pigtail stent $(10 \mathrm{Fr}$, Endo-Flex $\mathrm{GmbH}$, Germany) facilitated the drainage of the cyst.

\section{EUS-guided drainage process with plastic stent}

The echoendoscope was introduced to scan the abdominal cavity for the pseudocyst and mark the puncture point. The contact zone (i.e., the closest approximation of the region between the gastric wall and cyst wall) was identified. Color Doppler was applied to identify the interposing vessels and thus avoid them during puncture. An EchoTip Ultra endoscopic needle was then introduced via the working channel of the echoendoscope, and the cyst was punctured under EUS guidance. A sample of the cyst was aspirated for biochemical, cytological, and tumor marker analysis. If the cyst was very small, this sample was limited to avoid rapid cyst deflation, which can cause increased difficulty during stent placement. The guidewire was inserted through the needle lumen into the cyst and coiled into 2-3 loops, and the needle was removed. The needle path was then dilated by the cystotome and a balloon dilator. A double-pigtail stent $(10 \mathrm{Fr}$ ) was then introduced for drainage (Figure 1).

\section{EUS-guided drainage process with metal stent}

The initial steps were the same as the plastic stent placement. After the needle path was dilated by the cystotome, the stent $(10 \mathrm{~mm} / 35 \mathrm{~mm}$; Micro-Tech/Nan Jing CO., Ltd.) was slowly deployed into the cyst under the guidance of EUS until the distal flared end was completely open (Figure 2). Gentle traction was applied to pull the cyst wall close to the gastric wall. Then, under endoscopic surveillance, the remainder of the stent was deployed, keeping the proximal end in sight. The stomach was irrigated with saline, and EUS scanning was used to confirm the position of the stent and rule out further leakage. In some cases, a doublepigtail stent (PE double-pigtail $10 \mathrm{Fr} / 7 \mathrm{~cm}, 10 \mathrm{Fr} / 3 \mathrm{~cm}$ or $10 \mathrm{Fr} / 5 \mathrm{~cm}$, ENDO-FLEX GmbH, Germany) was introduced through the metal stent for auxiliary drainage.

\section{Statistical analysis}

Categorical variables were studied as percentage. Continuous variables were studied as mean with standard deviations. Independent variables used in the models included gender, age, etiology, size in EUS, and type of stents. Outcomes included reintervention and hospital days. Multivariate linear regression analysis was used to assess the relationship between clinical factors and hospital stay. The absolute value of $\mathrm{B}$ was used to predict the correlation. Logistic regression was used to test for effect associations among reintervention and independent variables. Absolute value of Exp B was used to predict the correlation. All reported
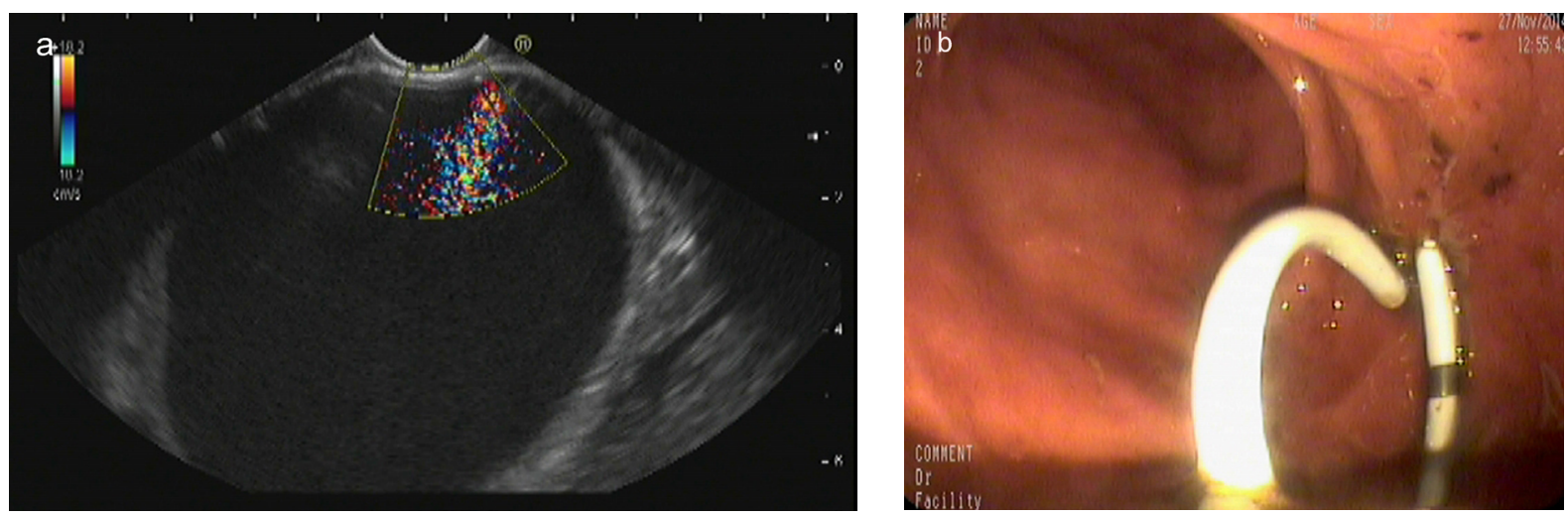

Figure 1. Endoscopic ultrasound-guided drainage process with plastic stent. (a) Pancreatic pseudocyst located at the body of pancreas; (b) a double-pigtail plastic stent was applied in the drainage. 

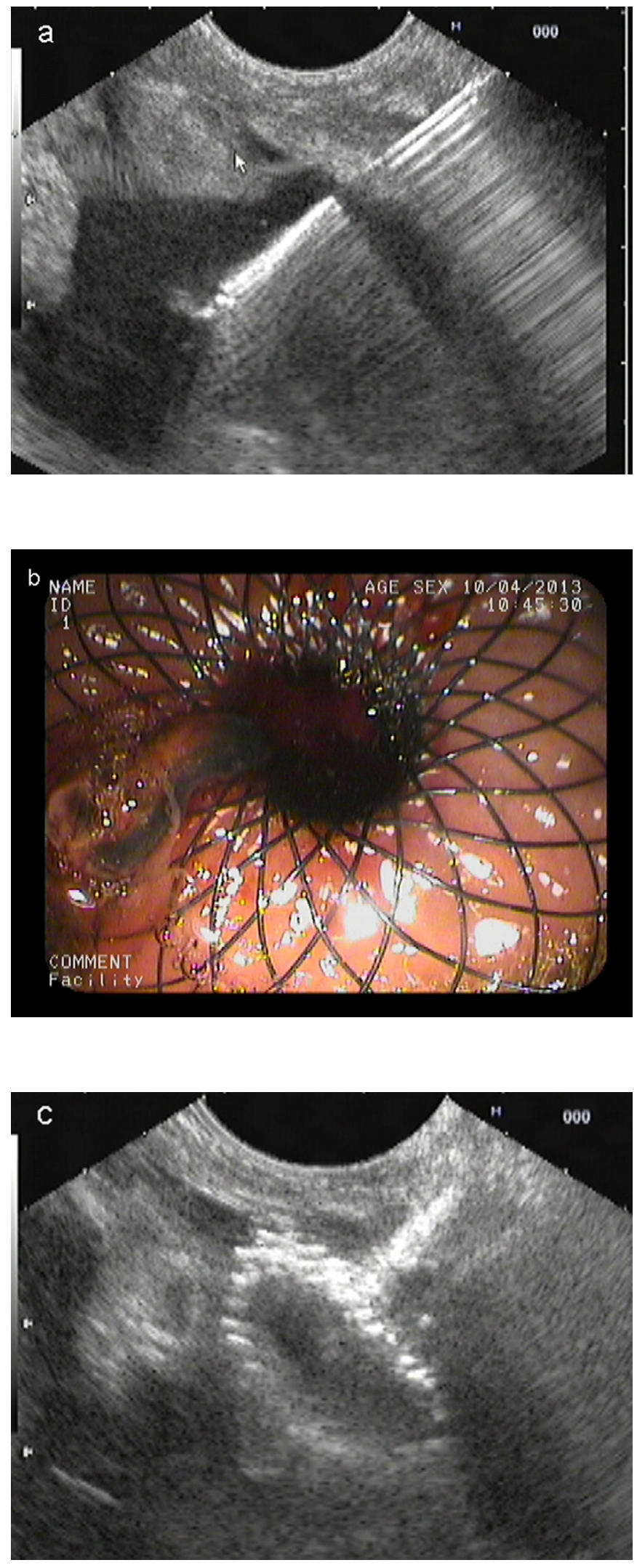

Figure 2. Endoscopic ultrasound (EUS)-guided drainage process with metal stent. (a) EUS-guided cyst puncture with needle; (b) endoscopic image of the metal stent; (c) EUS image of the metal stent.
$P$ values of $<0.05$ were considered to indicate statistical significance. Statistical analysis was performed using SPSS 21.0 software.

\section{RESULTS}

Fifty-two patients were enrolled in this study. The main characteristics of these patients are listed in Table 1. Metal or plastic stents were achieved in 52/52 (100\%) of the patients. Massive hemorrhage was observed in two patients during stent placement and was self-limited after the drainage was complete. Plastic stent migration into the cyst was found in one patient 2 weeks after drainage when the patient started to complain of obvious abdominal distention. Migration of the stent into the cyst was detected by CT. In order to retrieve the stent, a new fistula was created under EUS guidance. A regular endoscope was advanced into the cyst, and the stent was retrieved with foreign body forceps. Unfortunately, a devastating cyst hemorrhage occurred during retrieval of the stent. The hemorrhage was stopped using interventional vascular embolization. One patient with a plastic stent experienced leakage of a large amount of cyst fluid into the abdominal cavity after the procedure (Figure 3). The main complaints were abdominal pain and fever. The leakage and symptoms resolved following EUS-guided abdominal drainage with endoscopic nasobiliary drainage (ENBD). Clinical resolution occurred in all $52(100 \%)$ patients in this study (Table 2).

\begin{tabular}{ll}
\hline \multicolumn{2}{l}{ Table 1: The characteristic of the patients } \\
\hline Characteristic \\
\hline Sex \\
Female $(n)$ & 23 \\
Male $(n)$ & 29 \\
Age (years) & $50.35 \pm 12.71$ \\
Size (mm) & $95.37 \pm 44.92$ \\
Etiology & \\
Pancreatitis & 45 \\
Trauma & 3 \\
Surgery & 4 \\
Dilation & 17 \\
Stent type & \\
Metal & 12 \\
Plastic & 40 \\
\hline
\end{tabular}

On multiple logistic regression analysis, stent type was associated with risk of reintervention $(P<0.05)$. Other factors such as cyst size and age were also found to be related. According to the $\mathrm{B}$ value, the use of a plastic stent increases the risk of reintervention. Another main factor for reintervention is cyst size. On multivariate linear regressions analysis, stent type was not related 
to the duration of hospital stay $(P>0.05)$. Among the associated factors, etiology of the pseudocyst showed most correlation with the length of hospital stay (Table 3).

\begin{tabular}{lll}
\hline \multicolumn{3}{l}{ Table 2: The main outcome of patients } \\
\hline \multicolumn{3}{l}{ Outcome } \\
\hline Technique success & $100.00 \%$ & $n=52$ \\
Clinical success & $100.00 \%$ & $n=52$ \\
Complications & $7.69 \%$ & $n=4$ \\
Hemorrhage & $3.85 \%$ & $n=2$ \\
Migration & $1.92 \%$ & $n=1$ \\
Cyst rupture & $1.92 \%$ & $(n=1)$ \\
Reintervention & $15.38 \% \quad(n=8)$ \\
Hospital stay (d) & $7.8 \pm 4.922$ \\
\hline
\end{tabular}

\section{DISCUSSION}

PPs develop secondary to fluid leakage or liquefaction from pancreatic necrosis after acute pancreatitis, chronic pancreatitis, surgery, or trauma. ${ }^{[9-12]}$ EUS has been accepted as an important tool in pancreas disease evaluation ${ }^{[13-15]}$ and EUS-guided transluminal treatment of PPs is an effective alternative to surgical treatment. ${ }^{[16-23]} \mathrm{A}$ CSEMS is primarily used if the contents of the collection are thick, necrotic, or infected, as these collections may not adequately drain through plastic stents. ${ }^{[2-26]}$ Recently, CSEMSs have come to be used in all kinds of PPs. CSEMSs have an advantage in that only a single stent may be required rather than multiple plastic stents. The self-expandable stent can occlude the tract between the stomach and the cyst, which may decrease the leakage from the cyst. Moreover, they provide a larger diameter compared to plastic stents. Therefore, they decrease the risk of occlusion and so might reduce the need for repeated procedures. In addition, the anastomosis created by a metal stent can facilitate the necrosectomy procedure within the cyst. Our study used the newly designed, LAMS, which has a dog-bone-like shape. These stents are also fully covered, with two large flare ends and a short waist. This kind of stent imparts lumen-to-lumen anchorage. In the meantime, other newly developed LAMSs has been applied in clinic as well. ${ }^{[6,7,27-29]}$ Technically, this design may be effective in anastomosis, even between two lumens that are physically separated. ${ }^{[30]}$ There has not been strong evidence thus far in the published literature that favors the lumen-apposing stent when compared with the plastic stent in resolving simple PPs. The choice of CESMs has continued to depend on the endoscopists' personal choice rather than evidenced-based findings.

EUS-guided PP drainage had a high technical success rate with either metal or plastic stents in our study. This result consistently matches reports from other centers $(77-100 \%) \cdot{ }^{[31-34]}$ As the CSEMs are shorter in length, the release of these stents should be more precise. Excess pushing of the stents will cause immediate migration. In
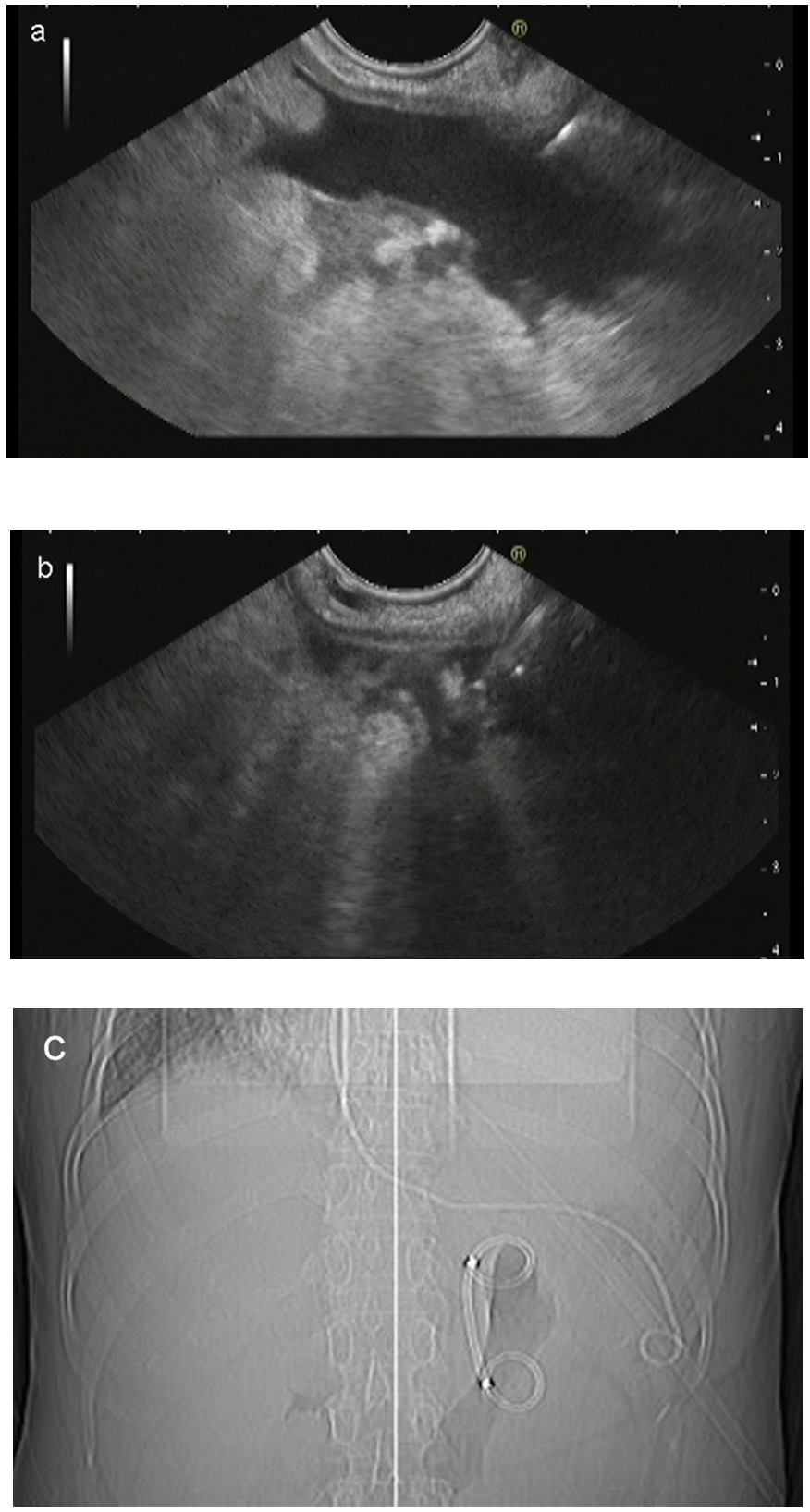

Figure 3. (a) Leakage of a large amount of cyst fluid into the abdominal cavity after the procedure; (b) endoscopic ultrasound-guided abdominal drainage with endoscopic nasobiliary drainage (ENBD); (c) X-ray image after the abdominal drainage.

our study, the whole process was performed by one skilled endosonographer under the surveillance of EUS imaging without fluoroscopic guidance. ${ }^{[21,35]}$ Both metal and plastic stents can be clearly visualized by EUS.

Migration is a common complication of drainage therapy ${ }^{[36-39]}$ There are two directions of migration, inside and outside the pseudocyst. Early migration outside the cyst will cause incomplete drainage and may need reintervention. Most migrations that occurred in our study 
Ge et al.: EUS-guided pancreatic pseudocyst drainage with lumen-apposing metal stents or plastic double-pigtail stents

\begin{tabular}{|c|c|c|c|c|c|c|c|c|}
\hline & \multicolumn{4}{|c|}{ Hospital stay } & \multicolumn{4}{|c|}{ Reintervention } \\
\hline & B & $95.0 \% \mathrm{Cl}$ & & $P$ & Exp B & $95.0 \% \mathrm{C}$ & & $P$ \\
\hline Sex & 1.169 & 0.762 & 1.577 & 0.000 & 0.245 & 0.157 & 0.381 & 0.000 \\
\hline Age & -0.063 & -0.079 & -0.046 & 0.000 & 0.891 & 0.874 & 0.908 & 0.000 \\
\hline Pancreatitis & -8.427 & -10.256 & -6.599 & 0.000 & 0.200 & - & - & 1.000 \\
\hline Trauma & -9.758 & -11.782 & -7.734 & 0.000 & 17.892 & - & - & 1.000 \\
\hline Surgery & -5.514 & -7.178 & -3.849 & 0.000 & 0.000 & - & - & 0.998 \\
\hline Size & 0.030 & 0.026 & 0.035 & 0.000 & 1.042 & 1.037 & 1.048 & 0.000 \\
\hline Stent type & $\begin{array}{l}-0.047 \\
-0.564\end{array}$ & & 0.469 & 0.858 & 3.952 & 2.572 & 6.071 & 0.000 \\
\hline
\end{tabular}

happened in the late stage when the cyst had successfully resolved. This kind of migration cannot be considered to be a side effect. Migration of the stent inside the cyst is a more curious side effect and may need further intervention. In our study, stent migration into the cyst occurred in a patient with double-pigtail plastic stents. On the other hand, even in the published articles, there have been no cases of migration of lumen-apposing stents. ${ }^{[0,41]}$ As a result, although the statistics has not yet been proven, it appears that the newly developed lumen-apposing stents are antimigratory.

Bleeding is another side effect that may occur in drainage therapy ${ }^{[42]}$ Large pseudocysts are often accompanied by portal vein hypertension and transmural varicose veins. Hemorrhage may occur in the creation of a fistula, but the hemorrhage becomes self-limited as soon as the stents are released. It has been reported that delayed hemorrhage may occur because of inner cyst wall injury by stents. Gastric or duodenal ulcers may occur a few days after placement because of friction from the end of the metal stents. Thus far, there has been only one reported case of bleeding associated with metal stents. ${ }^{[43-45]}$ In our experience, silicone plastic stents or metal stents with blunt ends would be effective in reducing the risk of bleeding caused by cystic or gastric wall injury. In the other studies, metal stents were effectively applied for the needle path bleeding caused by dilation. ${ }^{[46]}$

The clinical success rate was very high in our study. PPs can be resolved by both metal and plastic stents after 3 months of drainage. A systematic review by Bang et al. ${ }^{[47]}$ concluded that there was no difference in overall treatment success between patients treated with plastic stents versus metal stents $(81 \%$ [95\% CI, $77-84 \%]$ vs. $82 \%$ [95\% CI, $74-88 \%])$. There was also no difference in the rate of recurrence between plastic and metal stents. Evidence from this analysis does not support the routine placement of metal over plastic stents for transmural drainage of PPs or even walled-off pancreatic necrosis. In our study, we further revealed that these two types of stents differ in the recovery process after the initial endoscopic procedure. Metal stents are superior in reducing the risk of reintervention after the initial endoscopic procedure. The reintervention that occurred in the plastic stents group were all within a few days after the initial procedure and were mainly due to secondary infection of the cyst or a large leak of cyst fluid, resulting in infective ascites after the stent placement. However, timely reinterventions, including establishing a drainage path via redilation and EUS-guided abdominal cavity drainage via ENBD, were effective in resolving the infection and did not lead to extension of hospital stay. ${ }^{[48]}$ As a result, stent type in our study was not associated with the length of hospital stay post-procedure.

In this study, we also found that there are two factors, diameter and etiology of the cyst, that may significantly affect the outcome. Diameter is an important factor that was found to be closely associated with both hospital days and reintervention. It seems that larger cysts have a greater risk of becoming infected after the initial drainage and cannot be effectively resolved following one-time endoscopic management; repeat endoscopic interventions are usually needed. ${ }^{[49]}$ Some of these repeat interventions may extend the hospital stay. This associated factor has been seldom discussed in previously published articles. Another factor strongly associated with hospital days and reintervention that has not been studied before is the etiology of the pseudocysts. According to the data, patients with posttraumatic PPs may have the longest hospital stay, and after surgery patients with PP may have the shortest recovery time after drainage.

\section{Limitations}

This is a retrospective study with a limited number of patients. Cost analysis was not considered in this study. Metal stents are much more expensive than plastic ones; however, reinterventions after plastic stent placement may also increase the cost. Further studies should address these issues.

\section{CONCLUSION}

In our study, both plastic and LAMSs were proven to be highly effective in PP drainage. The LAMS is superior 
in preventing complications such as migration and cyst leakage as well as reducing reintervention after the initial endoscopic drainage. Furthermore, diameter of the PPs is an important factor associated with the main outcome (large cysts often need more endoscopic interventions and prolong the hospital stay in some cases). Posttraumatic PPs require more recovery time after EUS-guided drainage.

\section{Conflict of Interest}

None declared.

\section{REFERENCE}

1. Mukai S, Itoi T, Sofuni A, Itokawa F, Kurihara T, Tsuchiya T, et al. Expanding endoscopic interventions for pancreatic pseudocyst and walled-off necrosis. J Gastroenterol 2015; 50: 211-20.

2. Varadarajulu S. EUS followed by endoscopic pancreatic pseudocyst drainage or all-in-one procedure: a review of basic techniques (with video). Gastroint Endosc 2009; 69: S176-81.

3. Singhal S, Rotman SR, Gaidhane M, Kahaleh M. Pancreatic fluid collection drainage by endoscopic ultrasound: an update. Clin Endosc 2013; 46: 506-14.

4. Penn DE, Draganov PV, Wagh MS, Forsmark CE, Gupte AR, Chauhan SS. Prospective evaluation of the use of fully covered self-expanding metal stents for EUS-guided transmural drainage of pancreatic pseudocysts. Gastrointest Endosc 2012;76: 679-84.

5. Musumba C, Tutticci N, Nanda K, Kwan V. Endosonography-guided drainage of malignant fluid collections using lumen-apposing, fully covered self-expanding metal stents. Endoscopy 2014; 46: 690-2.

6. Yamamoto N, Isayama $\mathrm{H}$, Kawakami $\mathrm{H}$, Sasahira N, Hamada T, Ito $\mathrm{Y}$, et al. Preliminary report on a new, fully covered, metal stent designed for the treatment of pancreatic fluid collections. Gastrointest Endosc 2013;77: 809-14.

7. Itoi T, Binmoeller KF, Shah J, Sofuni A, Itokawa F, Kurihara T, et al. Clinical evaluation of a novel lumen-apposing metal stent for endosonography-guided pancreatic pseudocyst and gallbladder drainage (with videos). Gastrointest Endosc 2012; 75: 870-6.

8. Ang TL, Kongkam P, Kwek AB, Orkoonsawat P, Rerknimitr R, Fock KM. A two-center comparative study of plastic and lumen-apposing large diameter self-expandable metallic stents in endoscopic ultrasound-guided drainage of pancreatic fluid collections. Endosc Ultrasound 2016; 5: 320-7.

9. Adler DG, Siddiqui AA. What's in a name? Pancreatic pseudocysts, walled-off necrosis, and pancreatic fluid collections. Endosc Ultrasound 2016; 5: 215-7.

10. Zaheer A, Singh VK, Qureshi RO, Fishman EK. The revised Atlanta classification for acute pancreatitis: updates in imaging terminology and guidelines. Abdom imaging 2013; 38: 125-36.

11. Kloppel G. Pseudocysts and other non-neoplastic cysts of the pancreas. Semin Diagn Pathol 2000; 17: 7-15.

12. Baillie J. Pancreatic pseudocysts (Part I). Gastrointest Endoscopy 2004; 59: 873-9.

13. Rana SS, Sharma V, Sharma R, Gunjan D, Dhalaria L, Gupta R, et al. Gastric gastrointestinal stromal tumor mimicking cystic tumor of the pancreas: Diagnosed by endoscopic ultrasound-fine-needle aspiration. Endosc Ultrasound 2015; 4: 351-2.

14. Silviu UB, Daniel P, Claudiu M, Sandulescu L, Simona F, Stefan P, et al. Endoscopic ultrasound-guided radiofrequency ablation of the pancreas: An experimental study with pathological correlation. Endosc Ultrasound 2015; 4 : 330-5.
15. Alkaade S, Chahla E, Levy M. Role of endoscopic ultrasound-guided fine-needle aspiration cytology, viscosity, and carcinoembryonic antigen in pancreatic cyst fluid. Endosc Ultrasound 2015; 4: 299-303.

16. Kato S, Katanuma A, Maguchi H, Takahashi K, Osanai M, Yane K, et al. Efficacy, Safety, and Long-Term Follow-Up Results of EUS-Guided Transmural Drainage for Pancreatic Pseudocyst. Diagn Ther Endosc 2013; 2013: 924291.

17. Rana SS, Sharma V, Gorka S, Sharma R, Bhasin DK. Creation of multiple transluminal gateway during endoscopic ultrasound-guided drainage of pancreatic necrosis by enlarging tract of impending rupture in duodenum. Endosc Ultrasound 2015; 4: 257-9.

18. Bhutani MS, Arora A. New developments in endoscopic ultrasoundguided therapies. Endosc Ultrasound 2015; 4: 304-11.

19. Saftoiu A, Vilmann A, Vilmann P. Endoscopic ultrasound-guided drainage of pancreatic pseudocysts. Endosc Ultrasound 2015; 4: 319-23.

20. Eliason K, Adler DG. Endoscopic ultrasound-guided transmural drainage of infected pancreatic necrosis developing 2 years after acute pancreatitis. Endosc Ultrasound 2015; 4: 260-5.

21. Rana SS, Bhasin DK. Nonfluoroscopic endoscopic ultrasound-guided transmural drainage of pseudocysts: A pictorial technical review. Endosc Ultrasound 2015; 4: 92-7.

22. Teoh AY, Dhir V, Jin ZD, Kida M, Seo DW, Ho KY. Systematic review comparing endoscopic, percutaneous and surgical pancreatic pseudocyst drainage. World J Gastrointest Endosc 2016; 8: 310-8.

23. Saul A, Ramirez Luna MA, Chan C, Uscanga L, Valdovinos Andraca F, Hernandez Calleros J, et al. EUS-guided drainage of pancreatic pseudocysts offers similar success and complications compared to surgical treatment but with a lower cost. Surg Endosc 2016; 30: 145965.

24. Ge N, Liu X, Wang S, Wang GX, Guo JT, Liu W, et al. Treatment of Pancreatic Abscess with Endoscopic Ultrasound-guided Placement of a Covered Metal Stent Following Failed Balloon Dilation and Endoscopic Necrosectomy. Endosc Ultrasound 2012; 1: 110-3.

25. Krishnan A, Ramakrishnan R. EUS-guided endoscopic necrosectomy and temporary cystogastrostomy for infected pancreatic necrosis with self-expanding metallic stents. Surg Laparosc Endosc Percutan Tech 2012; 22: e319-21.

26. Itoi T, Nageshwar Reddy D, Yasuda I. New fully-covered self-expandable metal stent for endoscopic ultrasonography-guided intervention in infectious walled-off pancreatic necrosis (with video). J Hepatobiliary Pancreat Sci 2013; 20: 403-6.

27. Berzosa M, Maheshwari S, Patel KK, Shaib YH. Single-step endoscopic ultrasonography-guided drainage of peripancreatic fluid collections with a single self-expandable metal stent and standard linear echoendoscope. Endoscopy 2012; 44: 543-7.

28. Disibeyaz S, Oztas E, Kuzu UB, Ozdemir M. Closure of echoendoscoperelated duodenal free wall perforation by placement of a covered metallic stent. Endosc Ultrasound 2016; 5: 399-400.

29. Ge N, Wang S, Wang S, Wang G, Liu X, Guo J, et al. Endoscopic ultrasound-assisted cholecystogastrostomy by a novel fully covered metal stent for the treatment of gallbladder stones. Endosc Ultrasound 2015; 4: $152-5$.

30. Mukai S, Itoi T, Sofuni A, Tsuchiya T, Gotoda T, Moriyasu F. Clinical evaluation of endoscopic ultrasonography-guided drainage using a novel flared-type biflanged metal stent for pancreatic fluid collection. Endosc Ultrasound 2015; 4: 120-5.

31. Varadarajulu S, Wilcox CM, Tamhane A, Eloubeidi MA, Blakely J, Canon CL. Role of EUS in drainage of peripancreatic fluid collections not amenable for endoscopic transmural drainage. Gastrointest Endosc 2007; 66: 1107-19.

32. Fabbri C, Luigiano C, Cennamo V, Polifemo AM, Barresi L, Jovine E, et al. Endoscopic ultrasound-guided transmural drainage of infected pancreatic fluid collections with placement of covered self-expanding metal stents: a case series. Endoscopy 2012; 44: 429-33. 
33. McVay T, Adler DG. EUS-guided drainage of pancreatic fluid collections: Double pigtails, metal biliary, or dedicated transluminal stents? Endosc Ultrasound 2015; 4: 1-3.

34. Ahn JY, Seo DW, Eum J, Song TJ, Moon SH, Park DH, et al. Single-Step EUS-Guided Transmural Drainage of Pancreatic Pseudocysts: Analysis of Technical Feasibility, Efficacy, and Safety. Gut Liver 2010; 4: 524-9.

35. Consiglieri CF, Gornals JB, Busquets J, Pelaez N, Secanella L, De-La-Hera $\mathrm{M}$, et al. Fluoroscopy-assisted vs fluoroless endoscopic ultrasound-guided transmural drainage of pancreatic fluid collections: A comparative study. Gastroenterol Hepatol 2017; Sep 4. pii: S0210-5705(17)30186-3. [Epub ahead of print].

36. Varadarajulu S, Wilcox CM. Endoscopic placement of permanent indwelling transmural stents in disconnected pancreatic duct syndrome: does benefit outweigh the risks? Gastrointest Endosc 2011; 74: 1408-12.

37. Cahen D, Rauws E, Fockens P, Weverling G, Huibregtse K, Bruno M. Endoscopic drainage of pancreatic pseudocysts: long-term outcome and procedural factors associated with safe and successful treatment. Endoscopy 2005; 37: 977-83.

38. Rana SS, Bhasin DK, Sharma R, Gupta R. Factors determining recurrence of fluid collections following migration of intended long term transmural stents in patients with walled off pancreatic necrosis and disconnected pancreatic duct syndrome. Endosc Ultrasound 2015; 4: 208-12.

39. Tarantino I, Di Pisa M, Barresi L, Curcio G, Granata A, Traina M. Covered self expandable metallic stent with flared plastic one inside for pancreatic pseudocyst avoiding stent dislodgement. World J Gastrointest Endosc 2012; 4: 148-50.

40. Gornals JB, De la Serna-Higuera C, Sanchez-Yague A, Loras C, SanchezCantos AM, Perez-Miranda M. Endosonography-guided drainage of pancreatic fluid collections with a novel lumen-apposing stent. Surg Endosc 2013; 27: 1428-34.

41. Nelsen EM, Johnson EA, Walker AJ, Pfau P, Gopal DV. Endoscopic ultrasound-guided pancreatic pseudocyst cystogastrostomy using a novel self-expandable metal stent with antimigration system: A case series Endosc Ultrasound 2015; 4: 229-34.

42. Puri R, Mishra SR, Thandassery RB, Sud R, Eloubeidi MA. Outcome and complications of endoscopic ultrasound guided pancreatic pseudocyst drainage using combined endoprosthesis and naso-cystic drain. J Gastroenterology Hepatol 2012; 27: 722-7.

43. Yusuf TE, Baron TH. Endoscopic transmural drainage of pancreatic pseudocysts: results of a national and an international survey of ASGE members. Gastrointest Endosc 2006; 63: 223-7.

44. Vosoghi M, Sial S, Garrett B, Feng J, Lee T, Stabile BE, et al. EUS-guided pancreatic pseudocyst drainage: review and experience at Harbor-UCLA Medical Center. MedGenMed 2002; 4: 2 .

45. Weckman L, Kylanpaa ML, Puolakkainen P, Halttunen J. Endoscopic treatment of pancreatic pseudocysts. Surg Endosc 2006; 20: 603-7.

46. Saxena P, Kumbhari V, Khashab MA. EUS-guided drainage of a giant hemorrhagic pseudocyst by a through-the-scope esophageal metal stent. Gastrointest Endosc 2014; 79: 202-3.

47. Bang JY, Hawes R, Bartolucci A, Varadarajulu S. Efficacy of metal and plastic stents for transmural drainage of pancreatic fluid collections: a systematic review. Dig Endosc 2015; 27: 486-98.

48. Nan G, Siyu S, Xiang L, Sheng W, Guoxin W. Combined EUS-Guided Abdominal Cavity Drainage and Cystogastrostomy for the Ruptured Pancreatic Pseudocyst. Gastroenterol Res Pract 2013; $2013: 785483$.

49. Watanabe Y, Mikata R, Yasui S, Ohyama H, Sugiyama H, Sakai Y, et al. Short- and long-term results of endoscopic ultrasound-guided transmural drainage for pancreatic pseudocysts and walled-off necrosis. World J Gastroenterol 2017; 23: 7110-8.

How to cite this article: Ge N, Hu J, Sun S, Linghu E, Jin Z, Li Z. Endoscopic ultrasound-guided pancreatic pseudocyst drainage with lumen-apposing metal stents or plastic double-pigtail stents: A multifactorial analysis. J Transl Intern Med 2017; 5: 213-19. 